\title{
Defective polymorphonuclear leucocyte chemotaxis in rheumatoid arthritis associated with a serum inhibitor
}

\author{
S. M. HANLON, G. S. PANAYI, AND R. LAURENT \\ From the Department of Medicine and Arthritis Research Unit, Guy's Hospital Medical School, London \\ SE1 9RT
}

SUMMARY Cellular and/or serum components of polymorphonuclear leucocyte chemotaxis were assessed in 21 patients with rheumatoid arthritis. No difference in the chemotactic migration of control and patient cells in response to a number of chemotactic solutions could be detected ( $P=$ $0.38)$. Deficient generation of chemotactic activity in patient sera $(P=0.58)$ as compared to control sera $(P=0.014)$ after incubation of the sera with Escherichia coli lipopolysaccharide, resulted in a significant difference in the chemotactic activity of the control and rheumatoid serum preparations for polymorphonuclear leucocytes $(P=0.0012)$. This defect was associated with the presence of a serum inhibitor of chemotaxis, the potency of which was inversely correlated with the level of chemotactic activity generated in the rheumatoid sera $(\mathrm{r}=-0.941, \mathrm{P}<0.001)$.

Defective leucotaxis associated with serum chemotaxis inhibitors has recently been implicated in the altered immune responses and increased incidence of infection seen in a number of disease states (De Meo and Anderson, 1972; Smith et al., 1972; Van Epps et al., 1974; Ward and Berenberg, 1974; Van Epps et al., 1975; Maderazo et al., 1976; Ward et al., 1976). The demonstration of low levels of chemotactic factor inactivators in normal human serum suggests a regulatory role for these inhibitors in the inflammatory response.

Mowat and Baum (1971) reported decreased migration of the polymorphonuclear (PMN) leucocytes of 24 patients with rheumatoid arthritis (RA). In a subsequent study of neutrophil function in 4 patients with RA Goetzl (1976) found no difference between control and patient cells with respect to random migration, directed migration, and ascorbate enhancement of random and directed migration.

In view of these conflicting results and the pathological and therapeutic potentials of naturally occurring regulators of inflammation a re-examination of PMN leucocyte chemotaxis in RA was undertaken. This study confirms an abnormality of chemotaxis in RA, which, however, is not intrinsic to the PMN leucocyte but is associated

Accepted for publication 16 October 1978. Correspondence to Dr G. S. Panayi. with a reduction in the generation of chemotactic activity and the presence of an inhibitor of chemotaxis in the sera of some patients with rheumatoid arthritis.

\section{Materials and methods}

PREPARATION OF LEUCOCYTES

Heparinised blood (10 units heparin $/ \mathrm{ml}$ ) was mixed with $6 \%$ dextran $(1 \mathrm{ml} / 5 \mathrm{ml}$ blood $)$ and the red cells allowed to sediment at $37^{\circ}$ for 30 minutes. The leucocyte-rich supernatant was centrifuged at $500 \mathrm{~g}$ for 5 minutes and the cell button washed twice and resuspended in minimal essential medium (MEM) with HEPES buffer (Gibco-Biocult) at pH 7.3. The suspension was then adjusted to a cell count of $2 \times 10^{6} \mathrm{PMN}$ leucocytes $/ \mathrm{ml}$.

\section{CHEMOTACTIC ASSAY}

Chemotactic solutions were prepared from control and patient sera with or without LPS (lipopolysaccharide B, Escherichia coli 026: B6, Difco Laboratories) activation of the complement system. Except where otherwise indicated, $0.1 \mathrm{ml}$ serum was mixed with $0.1 \mathrm{ml}$ MEM or $0.1 \mathrm{ml} \mathrm{LPS}(100 \mu \mathrm{g} /$ $\mathrm{ml})$. These test solutions were incubated first at $37^{\circ} \mathrm{C}$ for 30 minutes, then at $56^{\circ} \mathrm{C}$ for 30 minutes and finally diluted to a total volume of $1.0 \mathrm{ml}$ 
with MEM. A negative control of MEM alone was used to assess spontaneous migration of cells.

A modification of the Boyden method known as the raft technique was used for the measurement of chemotaxis (Addison and Babbage, 1976). Antibiotic assay discs (Whatman) were placed in the wells of a plastic migration plate (Sterilin) and soaked with $200 \mu$ l of the test chemotactic solutions. Filters of pore size $3 \mu \mathrm{m}$ (Millipore) were placed on the discs and small chambers containing the cell suspensions were inverted on to the filters. After incubation in a moist box at $37^{\circ} \mathrm{C}$ for 75 minutes, the filters were stained and examined for the "leading front' of cell migration using a microscope fitted with a micrometer on the fine adjustment (Zigmond and Hirsch, 1973)

In every experiment a control was tested in parallel with 1 or 2 patients. Each cell-chemotactic solution combination was tested in duplicate and each filter examined in 5 random fields. The net chemotactic migration of cells was calculated by subtracting the distance migrated towards MEM (spontaneous migration) from the total distance migrated towards each test chemotactic solution.

\section{OTHER LABORATORY MEASUREMENTS}

$\mathrm{C} 3, \mathrm{C} 4, \mathrm{C} 9$, and C-reactive protein were measured by single radial immunodiffusion using monospecific antisera and levels of circulating immune complexes by a solid phase technique employing C1q (Hay et al., 1976).

\section{PATIENTS}

Hospitalised and clinic patients with classical or definite rheumatoid arthritis and without evidence of infection were studied. The control group was drawn from healthy hospital personnel as well as from a non-rheumatoid patient population (cerebrovascular disease (2) and lumbar spondylosis and back pain (3) ). The initial chemotactic assays of cell and serum function were performed on 21 patients and 17 controls. Eleven additional patients and 7 controls were used in subsequent inhibition experiments.

\section{STATISTICAL ANALYSIS}

Statistical analysis was carried out by the method of generalised least squares using the computer program GLIM. The Spearman rank correlation coefficient was used to determine correlations between variables.

\section{Results}

\section{CELL FUNCTION}

The PMN leucocytes of 15 patients and 11 controls were compared in their ability to migrate towards chemotactic solutions prepared from autologous and homologous sera. No difference between the control and patient cells could be demonstrated $(P=$ $0 \cdot 38$ ) whether the chemotactic stimulus used was non-activated or activated control or patient serum (Fig. 1).

\section{SER UM COMPONENT OF CHEMOTAXIS}

The sera of 15 patients and 11 controls were tested for chemotactic attraction of control normal cells. The chemotactic activity of $10 \%$ non-activated patient serum was not significantly different from that of $10 \%$ non-activated control serum $(P=0.099)$. When LPS was added to the sera before use, the directed migration of the PMN leucocytes towards $10 \%$ normal serum was significantly greater than towards $10 \%$ rheumatoid serum $(\mathrm{P}=0.0012)$ (Fig. 2). This difference was due to deficient generation of effective chemotactic activity in the patient sera. While incubating control serum with LPS significantly increased its chemotactic activity $(P=0 \cdot 014)$, there was no difference in the chemotactic activity

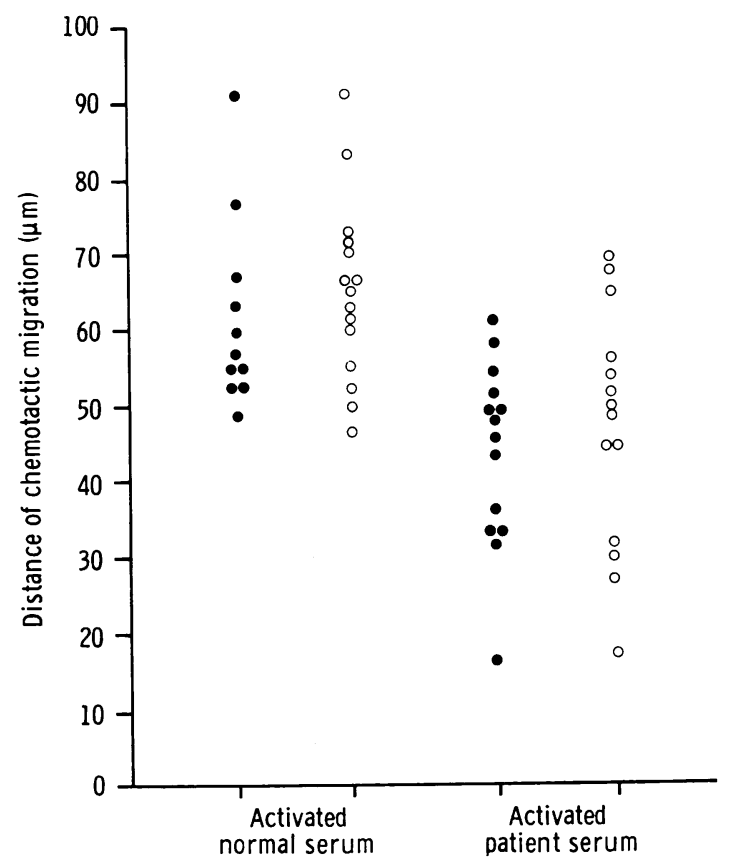

Fig. 1 A comparison of the chemotactic migration of normal (๑) and rheumatoid (0) PMN leucocytes in response to lipopolysaccharide-activated normal and patient sera. There was no difference in the migration of normal and patient cells $(P=0 \cdot 38)$ whether the chemotactic stimulus was non-activated or activated $10 \%$ normal or patient serum. 


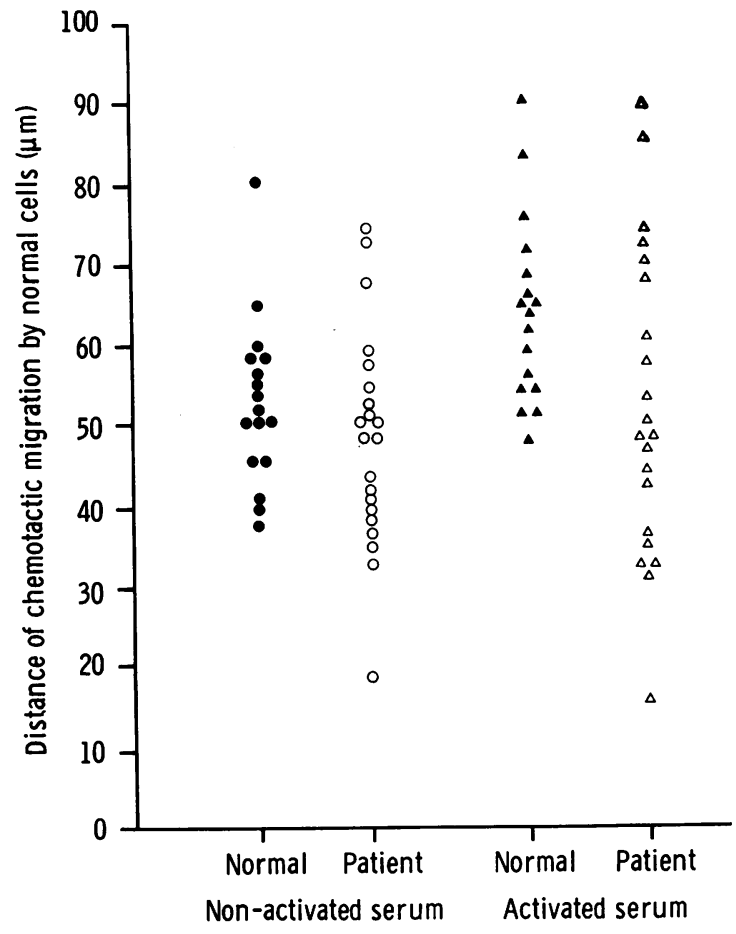

Fig. 2 A comparison of the chemotactic response of normal PMN leucocytes to $10 \%$ non-activated normal sera (๑), $10 \%$ non-activated rheumatoid sera (0), $10 \%$ activated normal sera $(\Delta)$, and $10 \%$ activated rheumatoid sera $(\Delta)$. There was no difference between the chemotactic activities of $(\bullet)$ and $(0)(P=0.099)$ or $(0)$ and $(\Delta)(P=0.58)$. There were significant differences between $(\bullet)$ and $(\Delta),(P=0.014)$ and $(\Delta)$ and $(\Delta)(P=0.0012)$.

of non-activated and activated patient serum $(P=0 \cdot 58)$.

By plotting the distance of migration of control cells in response to non-activated against activated control and patient serum, a defect in the generation of chemotactic activity could be illustrated in nearly half $(10 / 21)$ of the rheumatoid sera (Fig. 3). Six of the patient sera showed poor chemotactic activity, which was unchanged or decreased by activation of the complement system with LPS. Three rheumatoid sera had normal chemotactic activity, which was reduced after incubation with LPS. All 9 defective sera had normal C3 levels. One patient had a low C4.

\section{DEMONSTRATION OF INHIBITOR}

The cells of 2 patients and 2 controls were tested against buffer alone and buffer with $150 \mu \mathrm{g} / \mathrm{ml}$ LPS below the filters. No difference in cell motility was

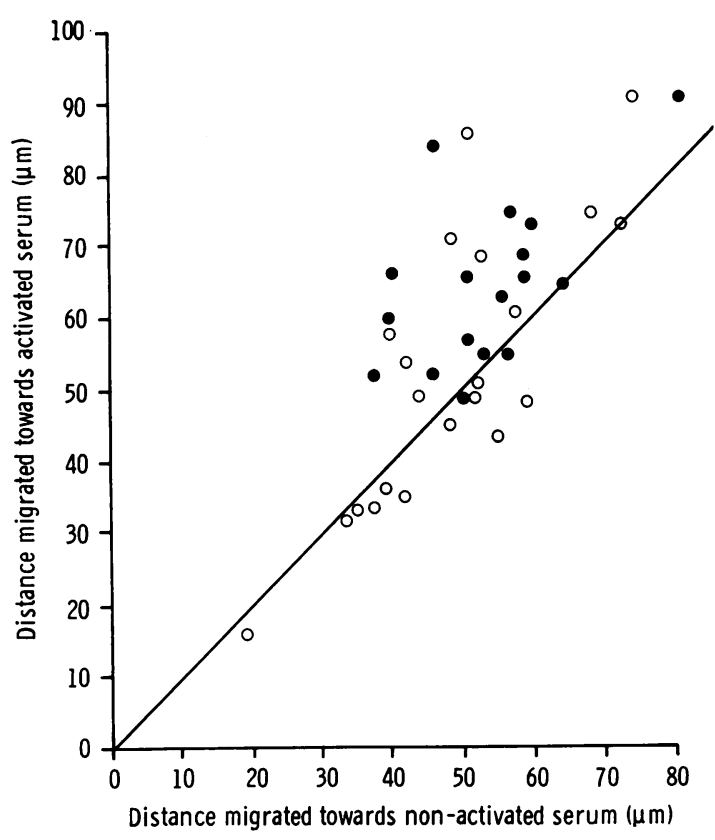

Fig. 3 This figure illustrates the relationship between the chemotactic activities of non-activated (horizontal axis) and activated (vertical axis) sera for both normal $(\bullet)$ and rheumatoid (0) sera. Points lying above the diagonal represent sera in which chemotactic activity has been generated by the addition of lipopolysaccharide. Points below the diagonal are sera in which the chemotactic activity has been reduced following incubation with lipopolysaccharide. Results were not dependent on drug therapy: patients 1 and 2 were each receiving $10 \mathrm{mg}$ prednisolone daily, patient 3 ibuprofen $1600 \mathrm{mg}$ daily, and patient 4 was receiving no drugs.

seen. It was concluded that the LPS itself did not adversely affect PMN leucocyte migration.

In order to demonstrate the presence of inhibitor in association with deficient chemotaxis 11 patient sera were collected and stored at $-70^{\circ} \mathrm{C}$ for testing on the same day with cells from a single normal donor. The patient sera and a normal pooled control serum were diluted to $20 \%$ concentration with and without added LPS and incubated at $37^{\circ} \mathrm{C}$ and $56^{\circ}$ $\mathrm{C}$ as previously described. All the serum solutions were diluted $1: 1$ with buffer to give $10 \%$ non-activated and activated test solutions. The $20 \%$ activated control serum was also diluted 1:1 with each of the activated patient sera resulting in mixtures containing $10 \%$ activated control and patient serum. All of these test chemotactic solutions then underwent a final incubation at $37^{\circ} \mathrm{C}$ for 30 minutes before use in the assay. Percentage of inhibition by each of the activated patient sera when mixed 
with the activated control serum was calculated according to the formula:

$1-\frac{\text { distance migrated towards mixed activated sera }}{\text { distance migrated towards } 10 \% \text { activated control }} \times 100$

Five of the patient sera showed an increase in chemotactic activity after incubation with LPS. Three of the activated patient sera manifested no or minimal inhibition of the control ( -7 to $12 \%)$. The remaining 8 activated patient sera reduced the chemotactic activity of $10 \%$ activated control serum by $27-55 \%$. The generated chemotactic activity of the rheumatoid sera showed a strong inverse correlation with the amount of inhibition of activated control serum $(r=0.941, P<0 \cdot 001$, Fig. 4).

An identical experiment was performed on serum from 7 normal donors. None of these sera were decreased in chemotactic activity by the addition of LPS and none inhibited the activated control serum.

In order to search for an inhibitor in non-activated patient sera, control serum was incubated with zymosan $(1 \mathrm{mg} / \mathrm{ml})$ at $37^{\circ} \mathrm{C}$ for 30 minutes, centrifuged, and decanted for use in the assay. Mixtures containing final concentrations of $10 \%$ activated control serum and $10 \%$ non-activated test serum were prepared for 3 patients and 3 normal persons. All 3 normal sera and one patient serum (which had previously shown normal generation of chemotactic activity with LPS) augmented the chemotactic activity of the activated control serum by more than

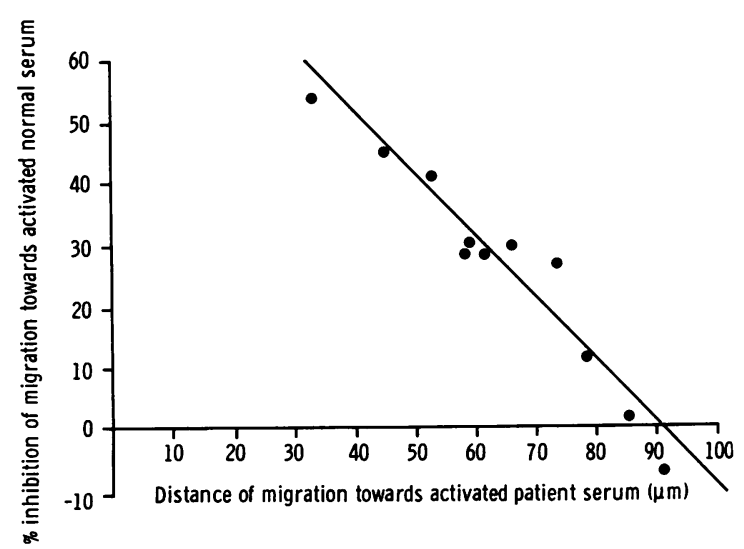

Fig. 4 The relationship between the generated chemotactic activity of rheumatoid sera (horizontal axis) and the percent inhibition of the chemotactic response to $10 \%$ activated normal serum to which $10 \%$ activated rheumatoid serum has been added. The migrating leucocytes are from normal donors $(r=0.941$, $P<0.00 I)$.
$20 \%$. The other 2 rheumatoid sera (both inhibitory in the activated form) did not augment the chemotactic activity of the activated control serum. This result is consistent with the presence of an inhibitor in these non-activated sera, since adding nonactivated serum usually leads to an increase in chemotaxis.

\section{CHEMOTAXIS AND DISEASE ACTIVITY}

Estimations of disease activity were done by measurement of CRP (McConkey, et al. 1972) and C9, thought to be an acute-phase reactant (Adinolfi and Lehner, 1976) and found to be elevated 2-4 fold in RA (Ruddy et al., 1971). These two laboratory parameters seemed to be of equal value in our study, since CRP level was strongly correlated with C9 $(r=0.936, P<0.001)$. No relationship could be found between level of CRP or C9 and the chemotactic or inhibitory activity of the patient sera. All 11 patients in the inhibition experiment had normal $\mathrm{C} 3$ and $\mathrm{C} 4$ levels. There was no correlation between $\mathrm{C} 3, \mathrm{C4}$, or level of circulating immune complexes and chemotactic activity or inhibition.

Analysis of patients' records showed that no patient had concurrent infection at the time of the study. Similarly, disease activity as judged clinically by the Ritchie index (Ritchie et al., 1968) and the presence of nodules and vasculitis was not related to the ability of the patients' sera to support or to inhibit chemotaxis. These clinical observations are consistent with the laboratory results already reported which were also unrelated to defective chemotaxis.

Since drugs which are used for the treatment of RA may inhibit neutrophil chemotaxis (Ward, 1966), it is important to consider their role in the observed effects. Two observations are pertinent. First, both the rheumatoid patients and many of the control subjects, who were patients attending the Rheumatology Department for inflammatory musculoskeletal disorders were taking analgesic antiinflammatory drugs such as indomethacin, aspirin, and ketoprofen. Secondly, the medication of individual patients bore no relationship to outcome in the chemotactic experiments. Thus, in Fig. 3, patients 1 and 2 were taking prednisolone (10 $\mathrm{mg}$ daily), but the non-activated serum of both patients showed good chemotactic activity. After activation only the serum from patient 1 generated good chemotactic ability. Furthermore, the sera of patient 3, who was receiving $1600 \mathrm{mg}$ ibuprofen, and of patient 4 , who was receiving no drugs at all, supported chemotaxis extremely poorly whether they were activated or not. Treatment with 'second-line' drugs such as Dpenicillamine or sodium aurothiomalate, also did not influence the generation of serum chemotactic 
activity. Similarly, generation of chemotacticinhibiting activity following endotoxin-activation of patients' sera was not related to medication.

\section{Discussion}

The mean chemotactic migration of PMN leucocytes from patients with rheumatoid arthritis did not differ significantly from the chemotactic migration of control cells in this study. The finding of normal migration by patient cells in this study is in apparent disagreement with the results of Mowat and Baum (1971) but agrees with those of Goetzl (1976). They described decreased chemotactic migration of the PMN leucocytes of 24 patients with adult onset of RA as compared to the cells of 24 controls using casein to the chemotactic stimulus. The difference may be partly accounted for by technical factors. First, the cell suspensions used in their experiments were prepared by 1:1 dilution of the leucocyte-rich plasma with buffer (Mowat and Baum, 1971; Baum et al., 1971). No washing of the cells was done in the interest of viability. Hence, the observed deficiency in cell motility may have been due to a plasma inhibitor of chemotaxis rather than to an intrinsic cell defect. It is of interest to note that these authors have also implicated a serum factor in the deficient chemotaxis of RA by demonstrating decreased chemotactic migration by normal cells which had been incubated in rheumatoid serum. Secondly, the discrepancies may be partly accounted for by the different method used in the quantitation of chemotaxis. Mowat and Baum used the lower filter surface count method, which may be more liable to errors than the leading front method used by ourselves (Wilkinson, 1974). Thirdly, the rate of neutrophil migration is dependent on the cell concentration placed on the upper filter (Zigmund and Hirsch, 1973), but Mowat and Baum did not control for this. It seems unlikely that the different chemotactic factor generating materials used (casein by them and LPS by ourselves) can account for the different results obtained, as these substances have been shown to produce comparable results (Baum, 1975).

Activation of the complement system with $E$. coli lipopolysaccharide (LPS) resulted in deficient generation of chemotactic activity in nearly half $(15 / 32)$ of the patient sera tested. This defect in chemotactic activity was associated with the presence of an inhibitor of chemotaxis, the potency of which was inversely related to the level of chemotactic activity generated in the patient sera. This serum defect has been reported by others (Mowat and Baum, 1971; Leimgruber et al., 1975), but its relationship to the presence of an inhibitor of chemotaxis has not been noted previously. There was no correlation between chemotactic activity or inhibition and disease activity as reflected in the measurement of acute phase reactants (c-reactive protein, $\mathrm{C}$, erythrocyte sedimentation rate) or the Ritchie index. This has been the experience of others in RA (Mowat and Baum, 1971) and in systemic lupus erythematosus (Clark et al., 1974). Leimgruber and his colleagues (1975) found that deficient chemotaxis was particularly noted during acute phases of the disease. In sequential studies of chemotaxis and anergy in acute systemic illnesses clinical improvement was accompanied by disappearance of inhibitor from the serum and return of skin reactivity (Van Epps et al., 1974).

The relationship between chemotactic sensitivity and disease activity in a chronic relapsing illness such as RA may be more difficult to determine. Similarly, there was no correlation between chemotactic activity or inhibition and plasma concentration of $\mathrm{C} 3, \mathrm{C} 4$, or the presence of soluble immune complexes. Similar conclusions for $\mathrm{C} 3$ and $\mathrm{C} 4$ have been reported previously (Leimgruber et al., 1975). The low C4 detected in 1 patient should not have affected alternate pathway activation of complement-derived chemotactic factors. Other workers have reported decreased generation of chemotactic activity in the sera of 10 of 23 patients with systemic lupus erythematosus following incu? bation with immune complexes or $E$. coli lipopolysaccharide (Clark et al., 1974). Again, no relationship was found with serum C3 or C4 levels.

The hypothesis that decreased chemotactic migration of PMN leucocytes in RA results from prior ingestion of immune complexes (Mowat and Baum, 1971; Roberts-Thomson et al., 1976) is not supported by this study. There was no defect in the migration of patient cells, which had been carefully washed before use in the assay. Furthermore no correlation was found between generated chemotactic activity or inhibitory activity of rheumatoid serum and level of immune complexes measured by a solid phase technique employing C1q. RobertsThomson et al. (1976) demonstrated a correlation between their chemotactic index and the monomer:dimer ratio of $\mathrm{IgG}$ as assayed by sepharose $6 \mathrm{~B}$ column chromatography at the $5 \%$ level of significance. However, these same authors found no significant correlation between the chemotactic index and level of immune complexes as measured by inhibition of $\mathrm{K}$ cell cytotoxicity.

The question of drug therapy is a vexatious one. Analysis of patients' records showed that poor generation of chemotactic activity was not related to it. Furthermore, any drugs present in the sera would not alter in concentration after activation by LPS. Yet generation of chemotactic inhibitor 
was especially noticeable after endotoxin activation of rheumatoid sera. It thus seems unlikely that effects observed here are due to drug therapy.

The ability of activated patient sera to decrease the response of cells to chemotactic factors derived from normal human serum is evidence for an inhibitory activity in these sera. The strong inverse correlation between this inhibition and the chemotactic activity generated in RA sera suggests that the deficiency in chemotactic activity is due not to a lack of chemotactic activity by the inhibitor. Rather it is probably due to counteraction of chemotactic activity by the inhibitor.

The incubation of some patient sera with LPS results in a reversal of chemotactic activity as compared with the non-activated patient sera, implying generation or unmasking of inhibitor. This could be explained by blocking of an inhibitor antagonist by LPS or by a complement fragment. The idea of an inhibitor suppressor is not new. Maderazo et al. (1975) have reported both a cell-directed inhibitor and its antagonist in normal human serum. The existence of a heat-labile antagonist of chemotactic inhibitor has been postulated by Van Epps and Williams (1976) to explain the penetration of the inhibitory activity present in serum after heating to $56^{\circ} \mathrm{C}$ in acute systemic illnesses.

Serum inhibitors of PMN leucocyte chemotaxis may act indirectly by affecting chemotactic factors or directly by inhibiting the cells. The chemotactic factor inactivator (CFI) found in small quantities in normal human serum (Berenberg and Ward, 1973) is composed of two fractions (Till and Ward, 1976) which directly and irreversibly inhibit bacterial and complement-derived chemotactic factors through an aminopeptidase action (Ward and Ozols, 1976). CFI is heat-labile at $56^{\circ} \mathrm{C}$ and has been found in increased levels in the serum of patients with Hodgkin's disease (Ward and Berenerg, 1974), sarcoidosis (Maderazo et al., 1976), and lepromatous leprosy (Ward et al., 1976). Cell-directed inhibitors of chemotaxis have been found in normal human serum (Maderazo et al., 1975), acute systemic illness associated with anergy (Van Epps et al., 1974; Van Epps and Williams 1976), alcoholic liver disease (Van Epps et al., 1975), and in a child with a recurrent infections (Smith et al., 1972). The inhibitors reported in all these studies were heat-stable at $56^{\circ} \mathrm{C}$. While the data presented here do not indicate the site of action of the inhibitory activity in RA serum, the heat stability of the inhibitor suggests it may be identical to one of the reported celldirected inhibitors.

This is the first description of a chemotactic inhibitor in RA. It is present in some native rheumatoid sera but it may be generated in others by activation of serum with LPS. In those sera with pre-existing inhibitory activity its magnitude is increased by activation. Work is currently in progress which investigates the activity of this inhibitor against other chemotactic stimuli such as casein, bacterial chemotactic factor, and $\mathrm{N}$-formyl methionyl peptides. Attempts are being made to characterise the nature of the inhibitor(s) in RA sera and the site of action (i.e., whether they act on the migrating neutrophil or chemotactic factor itself).

This study was financed by a grant from the Arthritis and Rheumatism Council of Great Britain. D.M.H. was supported by the Pillsbury Hospital Resident's Trust, Chicago. We thank Dr F. House, Department of Pharmacology, for his help in the statistical evaluation of the results.

\section{References}

Addison, I. E., and Babbage, J. W. (1976). A raft technique for chemotaxis: a versatile method suitable for clinical studies. Journal of Immunological Methods, 10, 385-388.

Adinolfi, M., and Lehner, T. (1976). Acute phase proteins and $\mathrm{C} 9$ in patients with Behçet's syndrome and aphthous ulcers. Clinical and Experimental Immunology, 25, 46-49.

Baum, J. (1975). Chemotaxis in human disease. In The Phagocytic Cell in Host Resistance, p. 283. Edited by J. A. Bellanti and D. H. Dayton. Raven Press: New York.

Baum, J., Mowat, A. G., and Kirk, J. A. (1971). A simple method for the measurement of chemotaxis of polymorphonuclear leukocytes from blood. Journal of Laboratory and Clinical Medicine, 77, 501-5.

Berenberg, J. L., and Ward, P. A. (1973). Chemotactic factor inactivator in normal human serum. Journal of Clinical Investigation, 52, 1200-1206.

Clark, R. A., Kimball, H. R., and Decker, J. L. (1974). Neutrophil chemotaxis in systemic lupus erythematosus. Annals of the Rheumatic Diseases, 33, 167-172.

De Meo, A. N., and Andersen, B. R. (1972). Defective chemotaxis associated with a serum inhibitor in cirrhotic patients. New England Journal of Medicine, 286, 735-740.

Goetzl, E. J. (1976). Defective responsiveness to ascorbic acid of neutrophil random and chemotactic migration in Felty's syndrome and systemic lupus erythematosus. Annals of the Rheumatic Diseases, 35, 510-515.

Hay, F. C., Nineham, L. J., and Roitt, I. M. (1976). Routine assay for the detection of immune complexes of known immunoglobulin class using solid phase C1q. Clinical and Experimental Immunology, 24, 396-400.

Leimgruber, A., Frei, P. C., Oschner, M., Schubert, M., and Saudan, Y. (1975). Chimiotactisme des polynucleaires humains in vitro. Etude dans les maladies rhumatismales inflammatoires. Schweizerische medizinische Wochenschrift.

Maderazo, E. G., Ward, P. A., Woronick, C. L. et al. (1975). Partial characterization of a cell-directed inhibitor of leukotaxis and its antagonist (abstract). In Fifteenth Interscience Conference on Antimicrobial Agents and Chemotherapy. American Society for Microbiology, No. 64. Bethseda, Maryland.

Maderazo, E. G., Ward, P. A., Woronick, C. L. et al. (1976). Leukotactic dysfunction in sarcoidosis. Annals of Internal Medicine, 84, 414-419.

McConkey, B., Crockson, R. A., and Crocksons, A. P. (1972). The assessment of rheumatoid arthritis. A study based on measurements of the serum acute phase reactants. Quarterly Journal of Medicine, 41, 115-125. 


\section{Hanlon, Panayi, Laurent}

Mowat, A. G., and Baum, J. (1971). Chemotaxis of polymorphonuclear leukocytes from patients with rheumatoid arthritis. Journal of Clinical Investigation, 50, 1541-1549.

Ritchie, D. M., Boyle, J. A., McInnes, J. M., Jasani, M. K., Dalakos, T. G., Grievson, P., and Buchanan, W. W. (1968). Clinical studies with an articular index for the assessment of joint tenderness in rheumatoid arthritis. Quarterly Journal of Medicine, 37, 393-406.

Roberts-Thomson, P. J., Hazleman, B. L., Barnett, I. G., MacLennan, I. C. M., and Mowat, I. G. (1976). Factors relating to circulating immune complexes in rheumatoid arthritis. Annals of the Rheumatic Diseases, 35, 314-320.

Ruddy, S., Everson, L. K., Schur, P., et al. (1971). Hemolytic assay of the ninth component: elevation and depletion in rheumatic diseases. Journal of Experimental Medicine, 134, 259s-275s.

Smith, C. W., Hollers, J. C., Dupree, E. et al. (1972). A serum inhibitor of leukotaxis in a child with recurrent infections. Journal of Laboratory and Clinical Medicine, 79, 878-885.

Till, G., and Ward, P. A. (1976). Two distinct chemotactic factor inactivators in human serum. Journal of Immunology, 114, 843-847.

Van Epps, D. E., Palmer, D. L., and Williams, R. C. Jr. (1974). Characterisation of serum inhibitors of neutrophil chemotaxis associated with anergy. Journal of Immunology, 113, 189-200.
Van Epps, D. E., Strickland, R. G., and Williams, R. C. Jr. (1975). Inhibitors of leukocyte chemotaxis in alcoholic liver disease. American Journal of Medicine, 59, 200207.

Van Epps, D. E., and Williams, R. C. Jr. (1976). Serum inhibitory activity: heat activation of chemotactic inhibition. Infection and Immunology, 13, 741-749.

Ward, P. A. (1966). The chemosuppression of chemotaxis. Journal of Experimental Medicine, 124, 209-224.

Ward, P. A., and Berenberg, J. L. (1974). Defective regulations of inflammatory mediators in Hodgkin's disease. Supernormal levels of chemotactic factor inactivator. New England Journal of Medicine, 290, 76-80.

Ward, P. A., Goralnick, S., and Bullock, W. E. (1976). Defective leukotaxis in patients with lepromatous leprosy. Journal of Laboratory and Clinical Medicine, 87, 10251032.

Ward, P. A., and Ozols, J. (1976). Characterizations of the protease activity in the chemotactic factor inactivator. Journal of Clinical Investigation, 58, 123-129.

Wilkinson, P. C. (1974). Chemotaxis and Inflammation, pp. 48-53. Churchill Livingstone: Edinburgh and London.

Zigmond, S. H., and Hirsch, J. G. (1973). Leucocyte locomotion and chemotaxis. New methods for evaluation and demonstration of a cell-derived chemotactic factor. Journal of Experimental Medicine, 137, 387-410. 